\title{
EFICACIA EXTRATERRITORIAL DE LAS SENTENCIAS MEXICANAS EN MATERIA DE ALIMENTOS. ESPECIAL CONSIDERACIÓN A LA CONVENCIÓN INTERAMERICANA SOBRE OBLIGACIONES ALIMENTARIAS*
}

\author{
Sonia RODRÍGUEZ JIMÉNEZ**
}

RESUMEN: Este artículo trata sobre la posibilidad de que las autoridades mexicanas dicten una sentencia en materia de alimentos a la luz de la Convención Interamericana sobre Obligaciones Alimentarias cuando se sustenta en la declaración interpretativa que hizo México a dicha convención. Así, nos planteamos dos interrogantes; la primera, qué eficacia tendrá una sentencia mexicana cuando reconoce alimentos a los concubinos y a los parientes colaterales hasta cuarto grado; la segunda, qué aplicabilidad tendrá la normativa material mexicana en otros tribunales, cuando resulta ser la normativa aplicable al fondo de un supuesto de alimentos, y éstos no lo reconocen en las categorías que mencionamos.

ABSTRACT: This paper deals with the possibility of getting a Resolution from Mexican authorities concerning the Inter-American Convention on Support Obligations, and the "support" meaning given by the Mexican interpretative declaration. Therefore, two questions arise. First, what is the efficacy of a decision that recognizes support to be given to concubines and close relatives up to the 4th degree. Second, what would be the applicability of Mexican laws overseas when they are the substantive applicable law for alimony, but its categories are not recognized elsewhere as valid categories?

RÉSUMÉ: Cet article traite de la possibilité qu'ont les autorités mexicaines d'émettre une décision de justice en matière de créances alimentaire dont la base légale serait l'interprétation de la Convention Interamericaine sur les obligations alimentaires. Il y a deux questions majeure: la première porte sur l'efficacité de la décision mexicaine quand elle reconnaît le droit d'aliments aux concubins et aux parents collatéraux jusqu'au quatrième degré. La deuxième traite de l'applicabilité de la matière normative mexicaine dans d'autres tribunaux, quand elle se révèle être la norme applicable au fond dans l'hypothèse d'aliments, et que ceux-ci ne le reconnaissent pas dans cette catégorie.

* El presente artículo surge de una inquietud suscitada tras la elaboración del libro titulado La protección del menor en el derecho internacional privado mexicano, UNAM, IIJ, en prensa.

** Doctora en derecho por la Universidad de Salamanca, España. Investigadora de tiempo completo en el Instituto de Investigaciones Jurídicas de la Universidad Nacional Autónoma de México. 


\begin{abstract}
SUMARIO: I. Introducción. II. Convención Interamericana sobre Obligaciones Alimenticias. III. La declaración interpretativa de México. Más sombras que luces. IV. Ampliaciones convencionales. V. Ampliaciones y regulación autónomas.

VI. Conclusiones. VII. Bibliografía.
\end{abstract}

\title{
I. INTRODUCCIÓN
}

Estamos ante un tema en el que se entrecruza el derecho internacional público y el derecho internacional privado. Como son dos ramas autónomas e independientes tienen zonas de intersección donde es factible encontrar y analizar dos aspectos de mutuo interés. No son pocas las veces ni los temas en que se da una interactuación entre lo público y lo privado. Estas líneas son un claro exponente de estas afirmaciones. Lo anterior no quiere decir que no exista una gruesa línea delimitadora de las funciones, objeto y características de ambas ramas del derecho. A grosso modo, podemos afirmar que mientras el derecho internacional público se enfoca a estudiar las relaciones interestatales, el derecho internacional privado lo hace respecto a las relaciones entre particulares. ${ }^{1}$

El propósito que nos hemos trazado al inicio de este trabajo es analizar cuál es el alcance y efectos extraterritoriales de una sentencia dictada por un tribunal mexicano a la luz de la declaración interpretativa que realizó en virtud del artículo 3 de la Convención Interamericana sobre Obligaciones Alimentarias. ${ }^{2}$ En este sentido, y a modo de introducción del tema, afirmamos que México a la hora de firmar y ratificar dicha convención, hizo uso de la posibilidad otorgada en el artículo tercero convencional para ampliar los originales acreedores alimentarios previstos por la citada convención. De este modo, no sólo se quedó en los menores, en los cónyuges y quienes hayan sido tales (ex cónyuges), sino que lo amplió a tres nuevas categorías. La primera es a los concubinos, la segunda es a los parientes colaterales hasta el cuarto grado menores e incapaces y en tercer y último lugar a las relaciones entre adoptante y adoptado.

1 Afirmación última que debe sufrir cierta flexibilización. En este sentido, es de todos sabido que el Estado puede actuar con una doble potestad, iure imperii o de iure gestioni. En este último caso, en el que actúa como particular, sin potestades soberanas, toda actividad que realice es objeto de estudio por el derecho internacional privado, siempre que concurra en su actividad el adjetivo de "internacionalidad".

2 Para consultar el texto de la declaración interpretativa, véase infra epígrafe III. 
Derivado de las anteriores afirmaciones es que nos preguntamos qué eficacia tiene o puede tener una sentencia mexicana en uno de los once Estados restantes que también tienen ratificado este instrumento convencional. Partiendo de la afirmación de que la materia familiar tiene un alto contenido de orden público, nos preguntamos con qué posibilidades las sentencias mexicanas, en virtud de dicha ampliación, toparán con dicha excepción.

Sin más preámbulo empezaremos con un tema propio de derecho internacional público, el de la distinción entre reservas y declaraciones interpretativas que se pueden realizar a los convenios, así como el alcance y efectos de las mismas. No siendo éste nuestro punto central, lo abordaremos de manera muy somera para poder centrarnos en el eje principal de estas líneas.

A falta de definición expresa de "declaración interpretativa", partimos de la figura de "reserva" donde contamos con un mayor interés transformado en una clara y contundente definición. De conformidad con el artículo 2.1.d) del Convenio de Viena sobre Derecho de los Tratados se entiende por reserva: "una declaración unilateral, cualquiera que sea su enunciado o denominación, hecha por un Estado al firmar, ratificar, aceptar o aprobar un tratado o al adherirse a él, con objeto de excluir o modificar los efectos jurídicos de ciertas disposiciones del tratado en su aplicación a ese Estado". Por su parte, el artículo 2 de la Ley sobre Celebración de Tratados afirma que reserva es "la declaración formulada al firmar, ratificar, aceptar o adherirse a un tratado, con objeto de excluir o modificar los efectos jurídicos de ciertas disposiciones del tratado en su aplicación a los Estados Unidos Mexicanos". Si esto se desprende de los principales cuerpos normativos; por parte de la doctrina, Reuter define las reservas como "la posición unilateral adoptada por un Estado con vistas a formar parte de tal acuerdo y por la que se limitan los compromisos a asumir por tal acto, bien interpretando de un modo determinado una disposición, bien excluyendo algunas otras". ${ }^{3}$ Igualmente contamos con la visión de Velásquez Elizarrarás quien afirma que las reservas a los tratados internacionales representan una de las instituciones más problemáticas, inacabadas y debatidas del orden jurídico internacional convencio-

3 Reuter, Paul, Derecho internacional público, Barcelona, Bosch, 1987, p. 125. 
nal. ${ }^{4}$ Para Remiro Brotóns la reserva "es uno entre los varios instrumentos ideados para propiciar la efectiva participación en los tratados multilaterales. A la misma familia pertenecen otras criaturas, algunas de las cuales guardan con la reserva un parecido que, en ocasiones, hace difícil distinguirlas: declaraciones interpretativas, opción entre disposiciones diferentes, admisión del compromiso parcial". 5

Partimos de que México denominó declaración interpretativa a esta ampliación de acreedores alimentarios; no entraremos a discutir profundamente si efectivamente es o no una declaración interpretativa o es una reserva camuflada tras rasgos semánticos. Entrar en este detallado debate sería sumergirnos en las complicadas aguas del derecho internacional público, lo cual desbordaría el objetivo central de este trabajo. Tampoco entraremos en una discusión a fondo de si es o no lo mismo una reserva que una declaración interpretativa, ${ }^{6}$ finalmente éstos no son nuestros principales objetivos. $^{7}$

Podemos comenzar afirmando que por las definiciones expuestas en líneas precedentes, todo apunta a que efectivamente se trata de una declaración interpretativa; en segundo lugar afirmamos que las reservas y las declaraciones interpretativas no son una misma figura jurídica, aunque en ocasiones sea muy difícil distinguirlas, y muy fácil camuflarlas y confundirlas. Veamos por qué. En este sentido el profesor Manuel Becerra atinadamente señala la diferencia entre reserva y declaración interpretativa, afirmando que:

4 Velázquez Elizarrarás, Juan Carlos, "Riquelme Cortado, Rosa, Las reservas a los tratados. Lagunas y ambigüedades del régimen de Viena", Anuario Mexicano de Derecho Internacional, México, 2006, p. 887.

5 Remiro Brotóns, Antonio, Derecho internacional público, Madrid, Tecnos, 1987, p. 206.

6 Velázquez Elizarrarás, Juan Carlos, op. cit., nota 4, p. 888, donde afirma: “es innegable también que los Estados o las organizaciones expresan a menudo su intención en forma ambigua, de ordinario obedeciendo a consideraciones políticas internas, en particular por medio de "declaraciones interpretativas" que no tendrían ningún sentido si no fuesen, de hecho reservas".

7 Como señala el profesor Manuel Becerra: "si bien es importante la definición que da el Estado de su expresión, no es definitiva; al juzgador le toca analizar si el título corresponde con la sustancia". Becerra Ramírez, Manuel, "Comentarios sobre la sentencia de la Suprema Corte de Justicia de la Nación en el caso de los 'Halcones",, Cuestiones Constitucionales. Revista Mexicana de Derecho Constitucional, México, UNAM, Instituto de Investigaciones Jurídicas, núm. 14, 2006, p. 219. 
La declaración interpretativa juega un papel importante en el proceso de interpretación y le ayuda a las partes a crear un clima de mutua comprensión en relación con la extensión de sus compromisos derivados del tratado así como el grado de involucramiento. En cambio, mediante una declaración interpretativa no se modifican los efectos de las obligaciones impuestas por un tratado; además, normalmente no obligan a las otras partes... Ésta no va más allá de "armonizar su derecho interno con las disposiciones de la convención" quien la hace, en ningún caso podrá "excluir o modificar los efectos jurídicos de las disposiciones de la convención en su aplicación a ese estado", lo que sí es posible con la reserva. ${ }^{8}$

De las palabras del profesor Manuel Becerra se desprenden sin duda tres características que serán fundamentales en la comprensión del alcance y efectos de la declaración interpretativa mexicana a la Convención Interamericana sobre Obligaciones Alimentarias. Además servirán de apoyo a las afirmaciones realizadas en la primera línea de este párrafo. En primer lugar supone únicamente una declaración unilateral sobre la extensión de los compromisos mexicanos ad extra; en segundo lugar, no obliga a las restantes partes contratantes de la citada convención; y tercero y último supone una armonización ad intra respecto al derecho civil. En este orden de ideas afirmamos que en el caso concreto de la Convención Interamericana sobre Obligaciones Alimentarias, la denominada declaración interpretativa es efectivamente esta figura y no una reserva encubierta; estamos ante una declaración unilateral, la cual tiene por objeto ampliar, no extinguir o modificar, los efectos jurídicos a los acreedores alimenticios, en su aplicación a ese Estado.

\section{CONVENCIÓN INTERAMERICANA SOBRE OBLIGACIONES ALIMENTARIAS $^{9}$}

\section{Introducción}

Debemos iniciar este apartado señalando las características básicas de este instrumento convencional para poder apreciar con toda nitidez el

8 Ibidem, pp. 218 y 219.

9 Para ver los aspectos históricos de la elaboración de esta convención, véase Santos Belandro, Rubén, "Reclamaciones de alimentos en el ámbito iberoamericano", en Calvo Caravaca, Alfonso Luis y Castellanos Ruiz, Esperanza (dirs.), El derecho de familia ante el siglo XXI: aspectos internacionales, Colex, 2003, pp. 775 y 776. 
problema que planteamos al inicio del trabajo. Abandonamos el terreno del derecho internacional público para adentrarnos en el del derecho internacional privado.

Estamos ante una convención procedente del foro de codificación de la CIDIP, concretamente de la CIDIP IV, celebrada en Montevideo, Uruguay, en 1989. En esta misma cumbre negociadora se aprobaron dos convenciones más: la Convención Interamericana sobre Restitución Internacional de Menores y la Convención Interamericana sobre Contratación de Transporte Internacional de Mercaderías por Carretera. De los cuales México tiene ratificados los dos instrumentos atinentes a menores.

Lo primero que debe afirmarse de este instrumento es que estamos en presencia de una convención de contenido tripartito, es decir, regula la competencia judicial internacional, el derecho aplicable y la cooperación procesal internacional. ${ }^{10}$ Esta característica la convierte en una de las convenciones interamericanas más completas al abordar tres aspectos fundamentales del contenido del derecho internacional privado. Por lo afirmado con anterioridad determinamos que su aplicación desemboca necesariamente en la imposibilidad de fragmentar los cuerpos normativos aplicables para dar una respuesta integral a estos tres sectores. De esta forma, si todos los ámbitos de aplicabilidad convencional (el material-personal, el temporal y el espacial) se cumplieran, esta convención daría una respuesta integral al supuesto de hecho de alimentos. Si dicha convención no se aplicara, porque uno o varios criterios de aplicabilidad no se cumplieran, se daría forzosamente, en el caso mexicano, la fragmentación de cuerpos normativos, debiendo determinarse la competencia judicial internacional por el CPCDF, artículo 156; el derecho aplicable por el CCDF, artículo 13, y el reconocimiento y ejecución de la sentencia por el CPCDF, artículos 599 y ss.

\section{Criterios de aplicabilidad convencional}

\section{A. Ámbito de aplicación espacial}

Uno de los aspectos que se debe tener en cuenta para afirmar el éxito de un determinado instrumento convencional es el número de Estados

10 Esta amplia regulación contenida en apenas 33 artículos, le ha valido el hecho de que la doctrina afirme que "se trata, en suma, de una pequeña codificación internacional en materia de alimentos”. Santos Belandro, Rubén, op. cit., nota anterior, p. 776. 
que lo tiene incorporado como derecho positivo en su ordenamiento jurídico. En este sentido, la doctrina no ha dudado en afirmar la trascendencia de esta convención debido al número de países que a la fecha lo han ratificado. ${ }^{11}$ Afirmación a la que nos unimos debido fundamentalmente a dos consecuencias inevitables que dicho éxito detona. En primer lugar, la armonización y unificación que en materia de alimentos se tiene en la actualidad en gran parte de los países latinoamericanos. En segundo lugar, por la seguridad que produce el conocer de antemano la legislación aplicable, las reglas de juego.

Para nosotros este es un instrumento de carácter inter partes, basado en el criterio de la reciprocidad. ${ }^{12}$ En este sentido afirmamos que, de conformidad con el artículo primero, "el acreedor de alimentos debe tener su domicilio o residencia habitual en un Estado parte y el deudor de alimentos su domicilio o residencia habitual, bienes o ingresos en otro Estado parte". Así, se exige que los dos Estados implicados (el del acreedor y el del deudor) sean Estados parte de la convención. ${ }^{13}$ Afirmación que hacemos a pesar de que no está explícitamente aclarado en el texto de la convención dicho carácter inter partes. La doctrina señala respecto a este punto que "esta situación lacunaria puede llevar a que cada

11 Los Estados parte de esta convención son: Argentina, Belice, Bolivia, Brasil, Costa Rica, Ecuador, Guatemala, México, Panamá, Paraguay, Perú y Uruguay. Buis, Emiliano et al., "La República Argentina y la Convención Interamericana sobre Obligaciones Alimentarias (CIDIP IV)", en Calvo Caravaca, Alfonso Luis y Castellanos Ruiz, Esperanza (dirs.), op. cit., nota 9, p. 84. Véase www.oas.org/juridico/spanish/firmas/b-54.html (fecha de consulta: 19 de mayo de 2006).

12 Respecto a este punto, la doctrina se pregunta si el Convenio Interamericano es un convenio abierto o cerrado. En este sentido afirma que "el distingo entre una convención con efectos erga omnes o inter partes tiene su importancia debido a que el Estado ratificante de una convención debe aplicar siempre, en el primer caso, y en primer lugar, hayan los Estados vinculados ratificado la convención o no, al texto convencional y sólo en ausencia de regulación se podría recurrir al derecho interno... Tradicionalmente se reconoce mayores posibilidades de confeccionar una convención con efectos erga omnes sobre la ley aplicable que en materia de conflicto de jurisdicciones, debido a que esta última funciona generalmente sobre la base de criterios de reciprocidad". Santos Belandro, Rubén, op. cit., nota 9, p. 776.

13 Lo anterior nos sitúa en la afirmación de que es un instrumento que no tiene aplicación erga omnes, aun cuando reconocemos, como lo haría cierto sector doctrinal, que "todas las Convenciones de la CIDIP han descuidado este aspecto". En aras de una mayor seguridad hubiera sido muy recomendable que se hubiera determinado de manera expresa el ámbito de aplicación espacial de esta convención. Idem. 
Estado ratificante adopte una posición independiente sobre el tema, con los consiguientes perjuicios a una interpretación uniforme debido a los aspectos tan variados que comprende el tratado". ${ }^{14}$ Derivado de lo anterior, afirmamos que no se debe acudir ni al artículo 6 (derecho aplicable) ni al 8 (competencia judicial internacional) ni al 11 (competencia judicial indirecta) para determinar el carácter inter partes o erga omnes de esta convención. Lo anterior derivado de que cada uno de estos artículos se refieren a un sector del DIPr mientras que el artículo 1 se refiere más orientadamente a los ámbitos de validez y aplicación de este instrumento.

De cualquier forma, este ámbito de aplicación espacial nos da también el elemento de internacionalidad necesario para poder hacer nuestro el estudio de esta categoría jurídica.

\section{B. Ámbito de aplicación temporal}

Respecto a este segundo ámbito de aplicabilidad convencional señalamos que no se establece de manera expresa su carácter retroactivo o irretroactivo. Sabemos que este instrumento entró en vigor para México en 1996. Uniendo ambas afirmaciones señalamos que ante la falta de determinación expresa de su retroactividad debemos mantener su carácter irretroactivo. ${ }^{15}$ De esta forma todas aquellas solicitudes presentadas con anterioridad a esta fecha deberán efectuarse de conformidad con la normativa de derecho internacional privado autónomo mexicano y aquéllas solicitudes de prestación de alimentos realizadas con posterioridad a esa fecha se podrán basar (a reserva del cumplimiento de los otros requisitos aplicativos cumulativos) en el contenido de la convención.

Respecto a su entrada en vigor, el artículo 31 dispone que "entrará en vigor el trigésimo día a partir de la fecha en que haya sido depositado el segundo instrumento de ratificación. Para cada Estado que ratifique la

14 Ibidem, p. 777.

15 Ante este silencio convencional debemos aplicar la sección segunda, "Aplicación de los tratados", artículo 28 "irretroactividad de los tratados" del Convenio de Viena sobre Derechos de los Tratados. Artículo 28 del convenio de Viena de Derechos de los Tratados de 23 de mayo de 1969: "las disposiciones de un tratado no obligarán a una parte respecto de ningún acto o hecho que haya tenido lugar con anterioridad a la fecha de entrada en vigor del tratado para esa parte, no de ninguna situación que en esa fecha haya dejado de existir, salvo que una intención diferente se desprenda del tratado o conste de otro modo". 
convención o se adhiera a ella después de haber sido depositado el segundo instrumento de ratificación, la convención entrará en vigor el trigésimo día a partir de la fecha en que tal Estado haya depositado su instrumento de ratificación o adhesión". Criterio uniforme para todas las Convenciones Interamericanas que reproducen literalmente lo dispuesto en este artículo. ${ }^{16}$ Lo anterior deriva en la afirmación de que estamos ante una "cláusula tipo" del foro de codificación de la CIDIP. ${ }^{17}$

\section{C. Ámbito de aplicación material-personal}

Entremos de lleno en este tercer y último ámbito de aplicación convencional, el ámbito material-personal. Reconocemos en este punto la estrategia de dejar al final el que se supone que debe ser el primer ámbito de aplicación en estudiarse en toda convención que se precie. En este sentido, sostenemos que es fundamental saber la cobertura que México ha dado a esta convención, eje central sobre el que gira el presente trabajo.

Respecto a este tercer y último de los requisitos aplicativos convencionales podemos señalar que se aplicará a aquellos supuestos de hecho que se definan como "obligaciones alimenticias" enfocadas a priori a menores por su calidad de tales y a las relaciones matrimoniales entre cónyuges o quienes hayan sido tales (ex cónyuges). Desmenuzaremos dicha afirmación para entender con corrección el alcance de este ámbito de aplicación.

El concepto de "alimento" no aparece definido en la convención. No perdamos de vista que estamos ante un supuesto de hecho caracterizado por producirse entre particulares con un elemento de internacionalidad o extranjería, un elemento perturbador, que hace posible la intervención de más de dos ordenamientos jurídicos. Lo anterior supone el levantamiento de la situación que planteamos ante la posibilidad de que cada Estado contemple una cobertura diferente para el concepto de alimento. ${ }^{18}$ No

16 Fernández Arroyo, Diego Pedro, La codificación del derecho internacional privado en América Latina, Eurolex, 1993, p. 194.

17 Idem.

18 Por ejemplo, en el caso argentino, en lo referente a la conceptualización de la obligación de prestación de alimentos encontramos el artículo 267 del Código Civil argentino, el cual señala que "la obligación de alimentos comprende la satisfacción de las necesidades de los hijos en manutención, educación y esparcimiento, vestimenta, 
contamos con una calificación autárquica convencional del concepto de alimentos. Dos son las afirmaciones que se desencadenan de la anterior. En primer lugar señalamos que estamos en presencia de una técnica de reglamentación indirecta que da absoluta libertad a las normativas materiales estatales para que determinen el alcance de dicho concepto. En se-

habitación, asistencia y gastos por enfermedad". En el Código de Familia de Bolivia, capítulo III, encargado de la regulación de la "Asistencia familiar", trata la categoría de los alimentos, concretamente en el artículo 14 señala la extensión de la asistencia afirmando que comprende "todo lo indispensable para el sustento, la habitación, el vestido y la atención médica"; continúa afirmando que "si el beneficiario es menor de edad, esta asistencia también comprende los gastos de educación y los necesarios para que adquiera una profesión u oficio"; de conformidad con el Código Civil de 1956 guatemalteco destacamos el artículo 206 que afirma que "la denominación de alimentos comprende todo lo que es indispensable para el sustento, habitación, vestido, asistencia médica y también la educación e instrucción del alimentista cuando es menor de edad"; para el caso de Costa Rica, el Código de Familia, en su título IV, capítulo único, artículo 164, se afirma que "se entiende por alimentos lo que provea sustento, habitación, vestido, asistencia médica, educación, diversión, transporte y otros, conforme a las posibilidades económicas y el capital que le pertenezca o posea quien ha de darlos. Se tomarán en cuenta las necesidades y el nivel de vida acostumbrado por el beneficiario, para su normal desarrollo físico y psíquico, así como sus bienes"; en el caso de Ecuador, se dispone en el artículo 369 de su Código Civil que "los alimentos se dividen en congruos y necesarios. Congruos son los que habilitan al alimentado para subsistir modestamente, de un modo correspondiente a su posición social. Necesarios, los que le dan lo que basta para sustentar la vida. Los alimentos, sean congruos o necesarios, comprenden la obligación de proporcionar al alimentario menor de dieciocho años, cuando menos, la enseñanza primaria". Por su parte, Panamá, en su Código de Familia, artículo 377. Los alimentos comprenden una prestación económica, que debe guardar la debida relación entre las posibilidades económicas de quien está obligado a darlos y las necesidades de quien o quienes los requieran. Éstos comprenden: 1. El suministro de sustancias nutritivas o comestibles, de atención médica y medicamentos; 2. Las necesidades de vestido y habitación; 3. La obligación de proporcionar los recursos necesarios con el fin de procurar la instrucción elemental o superior o el aprendizaje de un arte u oficio, aun después de la mayoría de edad hasta un máximo de veinticinco (25) años, si los estudios se realizan con provecho tanto en tiempo como en el rendimiento académico, salvo si se trata de un discapacitado profundo, en cuyo caso hasta que éste lo requiera; y 4. Tratándose de menores, todo lo necesario para lograr su desarrollo integral desde la concepción. La autoridad competente apreciará estas circunstancias y otras que estime convenientes para determinar las necesidades del que recibe los alimentos"; en el caso de Paraguay, se afirma en el artículo 256 que: "la obligación de prestar alimentos que nace del parentesco comprende lo necesario para la subsistencia, habitación y vestido, así como lo indispensable para la asistencia en las enfermedades. Tratándose de personas en edad de recibir educación, incluirá lo necesario para estos gastos"; en el Código Civil de Perú se dispone, artículo 472 "noción de alimentos". "Se entiende por alimentos lo que es 
gundo lugar, y en clara conexión con la anterior, señalar que dicha ausencia de conceptualización unida a la libertad en su determinación estatal puede suscitar una cuestión de calificación. La posibilidad para evitar dicha cuestión consiste en concretar el sentido del término "alimento" de conformidad con la normativa material del Estado que se declaró con competencia judicial internacional, a saber, de conformidad con lo establecido en su lex fori. Una solución simple y sencilla. Si bien es cierto que eso sería lo más lógico y evitaría completamente la aparición de un conflicto de calificaciones, nos preguntamos a la vista de la estructura de la convención, qué ocurre cuando el punto de conexión de la norma de conflicto contenida en la convención nos envía a la aplicación de una norma material que no es la lex fori, a sensu contrario, nos envía el punto de conexión a la aplicación de un derecho extranjero. A la hora de aplicar esta normativa material extranjera nos encontramos con que dicha normativa ofrece un concepto de "alimentos" y una cobertura de los mismos, completamente diferente al mantenido en la lex fori. Dos son las posibilidades que nuevamente encontramos; primera, puede ocurrir que la normativa material extranjera sea más benévola que la lex fori; segunda, por el contrario que la lex fori sea más generosa en el concepto de alimentos que la normativa material de ese tercer Estado. Ante este panorama nos preguntamos si optamos por la primera opción, aplicación simplista de la lex fori, o si por el contrario, damos la opción de aplicar lex fori o derecho extranjero. Para nosotros la respuesta debe encaminarse a abogar por el mantenimiento del principio del favor creditoris. En este sentido la primera opción es clara y sencilla pero no sabemos si materializa dicho principio debido a que no conocemos qué nos pudiera haber deparado la aplicación del derecho extranjero. La segunda, más compleja que la anterior desde que requiere el estudio de dos normas materiales, estimamos que da mayor cobertura al principio del favor creditoris desde que se aplicará la más favorable. Respecto a este problema de determinación y calificación la doctrina ha señalado que:

indispensable para el sustento, habitación, vestido y asistencia medica, según la situación y posibilidades de la familia"; en el capítulo II del Código de Familia de Uruguay se afirma, artículo 121, que "se entiende por alimentos todo lo que es indispensable para satisfacer las necesidades de sustento, habitación y vestido, y en el caso de los menores de edad, también los requerimientos para su educación, recreación y desarrollo". De las anteriores conceptualizaciones se desprende que a pesar de ser muy parecidos en sus líneas más generales, sí difieren en algunos puntos concretos. 
Cuando las convenciones no califican de una manera autónoma una relación jurídica, entre todas las vías posibles goza de gran predicamento la calificación realizada sobre la base de los conceptos que suministra la ley del foro. Como la Convención de Montevideo de 1989 no ha buscado definir los alimentos, sin duda que una calificación sobre la base de la ley del juzgador es posible, sin embargo, debemos advertir que ese camino no puede ser recorrido en su totalidad debido a que exista en ella una dislocación profunda entre juez competente y derecho aplicable. ${ }^{19}$

En el caso mexicano, podemos considerar que este concepto, y de conformidad con el artículo 308 del CCDF, los alimentos comprenden: I. La comida, el vestido, la habitación, la atención médica, la hospitalaria y en su caso, los gastos de embarazo y parto; II. Respecto de los menores, además, los gastos para su educación y para proporcionarles oficio, arte o profesión adecuados a sus circunstancias personales; III. Con relación a las personas con algún tipo de discapacidad o declarados en estado de interdicción, lo necesario para lograr, en lo posible, su habilitación o rehabilitación y su desarrollo; y IV. Por lo que hace a los adultos mayores que carezcan de capacidad económica, además de todo lo necesario para su atención geriátrica, se procurará que los alimentos se les proporcionen, integrándolos a la familia. ${ }^{20}$

En este sentido afirma el Poder Judicial mexicano que:

Conforme al artículo 309 del Código Civil, el obligado a dar alimentos cumple incorporando al acreedor alimentario a la familia o dándole una

19 Fernández Arroyo, Diego Pedro, op. cit., nota 16, p. 779.

20 Cfr. Pereznieto Castro, Leonel y Silva Silva, Jorge Alberto, Derecho internacional privado. Parte especial, México, Oxford, 2000, p. 193; y Álvarez de Lara, Rosa María, "Introducción a la Convención Interamericana sobre Obligaciones Alimentarias", México, Revista de Derecho Privado, año 6, núm. 7, 1995, p. 103. Respecto a la norma material autónoma mexicana que sobre alimentos se pronuncia, el Código Civil y el Código de Procedimientos Civiles, Pérez-Duarte señala: "son varias las interrogantes que se plantean de la sola lectura de los preceptos normativos relacionados con la obligación alimentaria, tanto en el Código Civil como en el de Procedimientos Civiles. Desde mi punto de vista, estas interrogantes contribuyen, en gran medida, a complicar los juicios, a enconar el conflicto familiar y perpetuar un estado de incertidumbre en las personas que acuden a tribunales en espera de encontrar soluciones a sus problemas". Cfr. Pérez-Duarte y Noroña, Alicia Elena, "La interpretación jurisdiccional en materia de alimentos", Revista de Derecho Privado, México, año 9, núm. 25, 1998, p. 79. 
pensión. Pero en el primer supuesto la obligación consiguiente no se concreta solamente a proporcionar habitación, sino que, de conformidad con el artículo 308 del propio ordenamiento, los alimentos comprenden la comida, el vestido, la habitación y la asistencia médica, en casos de enfermedad, agregándose los gastos necesarios para la educación de los hijos menores y los ligados a la obtención de algún arte o profesión honestos. ${ }^{21}$

El término "menor" no corre la misma suerte que el término "alimento" y es definido por la convención señalando "a quien no haya cumplido la edad de dieciocho años". En esta ocasión se opta por una norma de contenido material, una técnica de reglamentación directa. ${ }^{22}$ Técnica que evita el planteamiento de la problemática de calificación. Sin perjuicio de lo anterior, "los beneficios de esta convención se extenderán a quien habiendo cumplido dicha edad, continúe siendo acreedor de prestaciones alimentarias de conformidad a la legislación aplicable prevista en los artículos 6 y 7 '. ${ }^{23}$ Esta última frase representa a nuestro juicio una clara intención de otorgar cobertura a las personas discapacitadas y a los estudiantes una vez que han superado el límite de los 18 años. En este sentido encontramos el pronunciamiento judicial de un Tribunal Colegiado que señala:

Supuesto que dentro de las causales para la cesación de la obligación de dar alimentos a que se contrae el artículo 316 del código Civil para el Estado de Chiapas, no se encuentra expresamente la consistente en que el hijo

21 IUS 245721. Séptima Época, Sala Auxiliar, Semanario Judicial de la Federación, vol. 115-120, séptima parte, p. 9, aislada, civil, rubro: Alimentos, obligación de proporcionar los. Alcance. Interpretación del artículo 309 del código civil.

22 Landoni Sosa, Ángel, "Las convenciones interamericanas sobre obligaciones alimentarias y restitución internacional de menores aprobadas en la CIDIP IV celebrada en Montevideo del 9 al 15 de julio de 1989", Revista Uruguaya de Derecho Procesal, núm. 2, 1989, p. 145. Santos Belandro, Rubén, op. cit., nota 9, p. 782. Señala este autor las ventajas de esta calificación material del término "menor". Así afirma que "tiene la ventaja de recurrir a las legislaciones nacionales, siempre disímiles en este punto, y permitir que los Estados parte tengan claro, al momento de ratificar o aplicar la convención, quiénes son mayores o menores a los solos efectos alimentarios".

23 Artículo 2: "A los efectos de la presente convención, se considerará menor a quien no haya cumplido la edad de dieciocho años. Sin perjuicio de lo anterior, los beneficios de esta convención se extenderán a quien habiendo cumplido dicha edad, continúe siendo acreedor de prestaciones alimentarias de conformidad a la legislación aplicable prevista en los artículos 6 y 7”. 
haya llegado a la mayoría de edad; y aun cuando pudiera interpretarse la fracción II del citado precepto en relación con el numeral 438, fracción II del mencionado código, es decir, que la patria potestad se acaba por la mayor edad del hijo y con ello concluye el deber de darle alimentos, en razón de que al llegar a la mayoría de edad se supone que goza de absoluta independencia para disponer tanto de sus bienes como de su persona, y esta emancipación también supone su capacidad física, económica y jurídica para ser autosuficiente a efecto de allegarse los alimentos que necesite para su subsistencia; sin embargo, por ser los alimentos a los hijos una cuestión de orden público, debe considerarse que por el solo hecho de llegar a la mayoría de edad no debe suspenderse la obligación de suministrarlos, sino que en cada caso, deben examinarse las circunstancias en que se encuentran los hijos al llegar a esa edad, para saber si siguen necesitándolos, en la inteligencia que tanto los hijos como el cónyuge gozan de esa presunción independientemente de si aquellos son mayores o menores de edad, por lo cual es el deudor quien debe demostrar que ellos tienen recursos propios para poder, así desligarse de esa obligación. ${ }^{24}$

Otro pronunciamiento judicial viene a resaltar en su rubro "Alimentos para hijos mayores de edad. Su procedencia requiere que éstos acrediten que el grado de escolaridad que cursan es el adecuado a su edad", y en su contenido:

La obligación de proporcionar alimentos a los hijos mayores de edad no desaparece por el solo hecho de que lleguen a ella, en virtud de que su necesidad no se satisface automáticamente por la realización de esa circunstancia, toda vez que al igual que los hijos menores de edad, tienen la presunción de necesitar los alimentos. Sin embargo, los hijos mayores deben acreditar que se encuentran estudiando y que el grado de escolaridad que cursan es adecuado a su edad, pues atendiendo a que los alimentos deben ser proporcionados en razón a la necesidad del que debe percibirlos, no sería jurídico ni equitativo condenar al padre o deudor a proporcionar alimentos al hijo mayor que estuviera realizando estudios que no corresponden a su edad y situación. En conclusión, ante la controversia respecto a la procedencia o subsistencia del pago de alimentos para un hijo mayor que manifiesta encontrarse estudiando, éste debe demostrar, además de la calidad

24 IUS 219253. 8a. época, TCC, SJF, t. IX, mayo de 1992, p. 390, [A], civil, rubro: alimentos. Aun cuando los hijos alcancen la mayoría de edad, no cesa la obligación por parte del deudor alimentista de proporcionárselos, si todavía los necesita el emancipado (Legislación del estado de Chiapas). 
de hijo y de que el deudor tiene posibilidad económica de sufragar los alimentos que le reclama, que efectivamente se encuentra estudiado y que el grado de escolaridad que cursa resulta adecuado o corresponde a su edad. ${ }^{25}$

Un interrogante que se puede presentar a la hora de leer este artículo convencional y afirmar que establece un tope máximo de edad pero no un mínimo, es si los alimentos pueden ser reclamados desde el momento de producirse el nacimiento o se pueden reclamar incluso antes, en la etapa de gestación; si la mujer embarazada puede reclamar alimentos, para su hijo non nato; si se determinará por la lex fori o por la normativa extranjera los derechos de alimentos del nasciturus. ${ }^{26}$ Estas preguntas deben ser resueltas a nuestro parecer por la lex fori, si ésta resulta más favorable a la protección del nasciturus o por el derecho extranjero si fuera ésta la más beneficiosa para dicho acreedor de alimentos. Lo anterior en clara protección del futuro acreedor de alimentos. Problema, por ejemplo, que aparece explícitamente resuelto en la declaración interpretativa hecha por Panamá, la cual afirma que "en este sentido, la persona concebida que está por nacer (el nasciturus) tiene derecho a pensión alimenticia prenatal".

\section{LA DECLARACIÓN INTERPRETATIVA DE MÉXICO. MÁS SOMBRAS QUE LUCES}

Si bien afirmábamos al inicio que de forma apriorística esta convención se aplicaba a los menores y a las relaciones matrimoniales entre cónyuges o a quienes hubieran sido tales, el artículo 1 concede la posibilidad de, al suscribir, ratificar o adherirse a esta convención, restringir este ámbito de aplicación personal únicamente a los menores. ${ }^{27}$ México,

25 IUS 187332, novena época, Tribunales Colegiados de Circuito, Semanario Judicial de la Federación y su Gaceta, t. XV, abril de 2002, p. 1206, tesis I.3o.C.307 C, aislada, civil. En este sentido se encaminaba el pronunciamiento IUS 207116, octava época, tercera sala, Semanario Judicial de la Federación, t. VI, primera parte, julio a diciembre de 1990, p. 187, tesis 3a./J.41/90, jurisprudencia, civil, rubro: alimentos. Corresponde al deudor alimentario la carga de probar que los hijos mayores que acrediten se encuentran estudiando un grado escolar adecuado, no los necesitan.

26 Santos Belandro, Rubén, op. cit., nota 9, p. 783.

27 Como señala la profesora Álvarez de Lara: "la determinación de los deudores alimentarios fue motivo de un gran debate al elaborarse el proyecto de convención". $C f r$. Álvarez de Lara, Rosa María, op. cit., nota 20, p. 104. 
lejos de restringir dicho ámbito de aplicación, realiza una declaración interpretativa que aumenta, a nuestro parecer desorbitadamente, los acreedores alimentarios. En este caso se afirma que "el gobierno de México, declara de conformidad con el artículo 3 de la convención que reconoce como acreedores alimentarios además de los señalados, a los concubinos, a los parientes colaterales dentro del cuarto grado menores o incapaces y al adoptado en relación con el adoptante".

A nuestro juicio se aumenta con exceso el número de legitimados para reclamar con éxito alimentos en virtud de esta convención. Si bien nos queda claro que esta declaración se realizó a efectos de darle compatibilidad y armonización ad intra respecto a los Códigos Civiles de las entidades federativas, ${ }^{28}$ del Distrito Federal ${ }^{29}$ y del Código Civil Federal, ${ }^{30}$ y derivado de una concepción amplia de la familia, debemos señalar que es demasiado generoso el ámbito de los parientes colaterales hasta cuarto grado menores o incapaces. Es más, estamos ante una declaración extensiva del compromiso ad extra mexicano que no tendrá una buena acogida en el resto de Estados latinoamericanos que tienen también ratificado este instrumento. A pesar de reflejar la máxima favor creditoris, con la que estamos completamente de acuerdo, estimamos una carga excesiva el cuarto grado colateral. ${ }^{31}$ Distinto discurso manejamos cuando se trata de ampliar los acreedores alimentarios a los concubinos y a las relaciones entre adoptante y adoptado. De lo anterior se desprende una característi-

28 Véase, como ejemplos, el artículo 327 del Código Civil de Aguascalientes, los artículos 302 y 304 del Código Civil de Baja California, artículo 450 de Baja California Sur, artículos 402 y 405 del Código Civil de Coahuila, 298 y 301 del Código Civil Chiapas, artículo 305 del Código Civil de Colima, artículos 279 y 282 del Código Civil de Chihuahua, artículos 297 y 300 del Código Civil de Durango, artículo 359 del Código Civil de Guanajuato, artículos 391 y 394 del Código Civil de Guerrero, artículo 437 del Código Civil de Jalisco, artículo 305 del Código Civil de Sinaloa, artículo 226 del Código Civil de Yucatán, artículos 233 y 236 del Código Civil de Veracruz o artículos 298 y 301 del Código Civil de Tabasco. Como notable excepción tenemos el artículo 321 del Código Civil de Campeche que limita al tercer grado.

29 Véase artículos 302 a 305 del Código Civil del Distrito Federal.

30 Artículos 302 a 307 del Código Civil Federal. Así afirmamos que parece haber operado una correcta recepción del derecho convencional en el derecho interno. Se ve que México realizó una tarea de pulir su normativa convencional a la interna preexistente, con el objetivo de que no hubiera asperezas entre ambos cuerpos normativos.

31 En este sentido, parientes colaterales hasta el cuarto grado llega a señalar a los primos hermanos. 
ca única que nos gustaría señalar llegados a este punto. Si bien estamos de acuerdo con la prestación de alimentos a: a) menores de dieciocho años; $b$ ) cónyuges; $c$ ) ex cónyuges; $d$ ) concubinos; e) parientes colaterales hasta segundo grado y; f) adoptante-adoptado; la realidad por la que nos preguntamos es qué eficacia tendrá la sentencia mexicana que otorga alimentos a favor de concubinos y parientes colaterales hasta el cuarto grado, menores e incapaces ante la regulación, autónoma y convencional, que presentan los once Estados restantes que tienen ratificado el instrumento interamericano.

En el concreto caso mexicano, sostenemos que el hecho de que se contemplen los mismos acreedores en la legislación autónoma como en la convencional significa que se llevaron a cabo los ajustes necesarios que reclamaba Víctor Carlos García Moreno, fechas anteriores al depósito del instrumento de ratificación ante la Secretaría General de la OEA de esta convención por México. ${ }^{32}$ Dato que no podemos dejar pasar por las implicaciones que ello tiene. ${ }^{33}$

De la ampliación a los legitimados por México, nos surge la duda de la compatibilidad entre el artículo 22 convencional y las declaraciones

32 En este sentido, Víctor Carlos García Moreno afirmaba que "el hecho de que México ratifique la Convención Interamericana sobre Obligaciones Alimentarias en nada contraviene a la legislación nacional en materia de obligaciones de alimentos, ya que únicamente sería necesario realizar mínimos ajustes a la legislación civil, familiar y adjetiva. Por otra parte, el instrumento interamericano complementaría nuestro derecho positivo sobre la materia y lo haría efectivo más allá de nuestras fronteras a través de la cooperación procesal internacional". Cfr. García Moreno, Víctor Carlos, "La conveniencia de que México ratifique la Convención Interamericana sobre Obligaciones Alimentarias", Lex, Difusión y Análisis, 3a. época, año IV, núm. 33, 1998, p. 46. Cfr. García Moreno, Víctor Carlos, "Las obligaciones alimentarias entre México y Texas y su relación con la Convención Interamericana”, México, Responsa, año 3, núm. 13, 1998, p. 10. En este sentido, se encaminan las afirmaciones de otro sector doctrinal el cual afirma que "el motivo que nos impulsó a publicar nuestro trabajo es el de efectuar un aporte y plantear algunas interrogantes tendientes a que en materia de derecho internacional privado, no se resienta lo establecido por el derecho interno de los Estados, sino que lo que se trata de lograr, es armonizar los criterios de carácter universal con las características nacionales". Corbella de Simonet, Beatriz et. al., "Breves reflexiones sobre la CIDIP IV en materia de obligaciones alimentarias", Revista Uruguaya de Derecho Procesal, núm. 2, 1989, p. 251.

33 En este sentido, afirmamos la correcta incorporación de México a los convenios internacionales lo cual supone un gran conocimiento de los instrumentos internacionales y un acertado manejo de la política convencional. 
interpretativas realizadas por México. Es decir, cómo conjugamos el orden público con las ampliaciones de los legitimados alimentarios. El artículo 22 convencional señala "podrá rehusarse el cumplimiento de sentencias extranjeras o la aplicación del derecho extranjero previstos en esta convención cuando el Estado parte del cumplimiento o de la aplicación, según sea el caso, lo considerare manifiestamente contrario a los principios fundamentales de su orden público" (cursivas añadidas).

$\mathrm{Si}$ bien cualquier sentencia mexicana sobre alimentos respecto a menores, cónyuges y ex cónyuges tendrá eficacia extraterritorial en cualquiera de los otros once Estados, no podemos afirmar lo mismo respecto a los concubinos y a los parientes colaterales hasta el cuarto grado, menores o incapaces, predicando de ellos una suerte muy dispar. La categoría de los adoptados y adoptantes estimamos que, a pesar de no ser los acreedores de base convencional, no tendrán ningún problema de alimentos y por ende de eficacia extraterritorial de estas sentencias mexicanas. En este orden de ideas afirmamos la falta de congruencia y una posible declaración de no reconocimiento y ejecución de una sentencia mexicana por aplicación del correctivo del orden público cuando estamos ante la figura del concubinato y/o de los parientes de cuarto grado colateral, menores o incapaces. Falta de congruencia que no creemos que a estas alturas del partido se pueda producir respecto a las relaciones derivadas de las filiaciones adoptivas.

Yendo un poco más allá si ponemos la declaración interpretativa mexicana relacionada con el artículo 22 convencional (orden público) nos preguntamos si podría rehusarse a aplicar el derecho extranjero el juez uruguayo, argentino, venezolano, etcétera, cuando éste resulte ser la norma material mexicana, y, lo que nos parece más grave, si una vez dictada la sentencia con ese derecho material como base, con el consiguiente gasto de tiempo y dinero, si podría no reconocerse una sentencia mexicana en Uruguay, Argentina, etcétera, por el hecho de otorgar alimentos a un pariente colateral hasta cuarto grado menor o incapaz o a un concubino.

La cosa se complica y adquiere mayor relevancia desde que el artículo 22 prevé dos posibles declaraciones de la excepción de orden público, en dos momentos procesales distintos, la primera respecto al derecho aplicable y la segunda respecto al reconocimiento y ejecución de las sentencias. Lo anterior supone un doble control por los órganos judiciales respecto de este correctivo. 
Que la materia de alimentos es de orden público no deja lugar a duda en los diferentes pronunciamientos del Poder Judicial mexicano. ${ }^{34}$ Queremos reproducir el encabezado de un pronunciamiento judicial cuyo rubro es "Pensión alimenticia". Por ser de orden público, no puede eludirse su cumplimiento aludiendo cuestiones de tipo formal (legislación del estado de Yucatán). ${ }^{35}$

Como broche a lo afirmado respecto a los parientes colaterales debemos reproducir aquí una tesis aislada. En este sentido se afirma por los tribunales mexicanos que:

De conformidad con la legislación sustantiva civil del Estado de Chiapas, ante el fallecimiento del progenitor de los menores, la obligada en primer término a cubrir las necesidades alimenticias es la madre de éstos, y en ausencia de ésta o ante su imposibilidad, tal obligación corre a cargo de los ascendientes paternos y maternos, respectivamente, quedando comprometidos los parientes colaterales dentro del cuarto grado, como la última posibilidad; por tanto, para poder demandar a estos últimos, debe acreditarse previamente la falta o imposibilidad de los parientes más allegados. ${ }^{36}$

34 IUS 339993, 5a. época, 3a. sala, Semanario Judicial de la Federación, t. CXXV, p. 1852, [A], civil, rubro: alimentos, convenio nulos en caso de; IUS 187869, 9a. época, Tribunales Colegiados de Circuito, Semanario Judicial de la Federación y su Gaceta, t. XV, febrero de 2002, p. 758, tesis I 3o. C. 283 C, aislada, civil, rubro: alimentos para menores. Cuando no se allegaron los elementos suficientes al juicio para determinar la precedencia de ese derecho o fijar el monto de la pensión por ese concepto, el juzgador debe suplir, incluso, la falta de reclamación de ese derecho y los argumentos que tiendan a constituirlo, así como recabar las pruebas necesarias al respecto (legislación del Distrito Federal). IUS 219253, 8a. época, TCC, Semanario Judicial de la Federación, t. IX, mayo de 1992, p. 390, [A], civil, rubro: alimentos. Aun cuando los hijos alcancen la mayoría de edad, no cesa la obligación por parte del deudor alimentista de proporcionárselos, si todavía los necesita el emancipado (legislación del estado de Chiapas). IUS 180965, 9a. época, TCC, Semanario Judicial de la Federación y su Gaceta, t. XX, agosto de 2004, p. 1381, tesis VII, 3o. C.J/8, [J], civil, rubro: alimentos. Su pago extrajudicial no hace improcedente la acción legal para demandarlos (legislación del estado de Veracruz).

35 IUS 178387, 9a. época, Tribunales Colegiados de Circuito, Semanario Judicial de la Federación y su Gaceta, t. XXI, mayo de 2005, p. 1500, tesis XIV, 1a. A.C.17 C, aislada, civil.

36 IUS 197958, 9a. época, TCC, Semanario Judicial de la Federación y su Gaceta, t. VI, agosto de 1997, p. 655, tesis XX.10.139 C, [A], civil, rubro: alimentos. Caso en que procede demandar su otorgamiento a los parientes colaterales (legislación del estado de Chiapas). 


\section{AMPLIACIONES CONVENCIONALES}

Los países que tienen a la fecha la convención ratificada son Argentina, Belice, Bolivia, Brasil, Costa Rica, Ecuador, Guatemala, México, Panamá, Paraguay, Perú y Uruguay. Este bloque de doce Estados parte de esa convención deriva en el innegable éxito de este instrumento. Colombia, Haití y Venezuela la tienen a la fecha firmada mas no ratificada. $^{37}$

Es importante conocer el estatus en el que se encuentra esta convención en los doce Estados que a la fecha la tienen ratificada; ${ }^{38}$ lo anterior sirve para poder ver si por esta vía tenemos alguna posibilidad de otorgar eficacia extraterritorial a las sentencias mexicanas dictadas a la luz de la declaración interpretativa que realizó a la convención que comentamos.

\section{Argentina y Ecuador}

En el caso de Argentina, quien depositó su instrumento de adhesión el 5 de septiembre de 2002, señaló: "Designación de Autoridad Central. 5 de septiembre de 2002. Ministerio de Relaciones Exteriores, Comercio Internacional y Culto-Dirección General de Asuntos Jurídicos". ${ }^{39}$

El silencio desde la óptica convencional sobre una ampliación o reducción de los acreedores de alimentos implica que si no se aumentan éstos por vía de normativa autónoma será imposible reconocer y ejecutar una sentencia del Poder Judicial mexicano cuando ésta se pronuncie sobre alimentos para concubinos y para parientes colaterales hasta el cuarto grado, menores e incapaces. Acerca de la categoría de los adoptantes y adoptados, y a pesar del silencio convencional, con completa seguridad podemos apostar el reconocimiento y ejecución de las sentencias mexicanas sin traba alguna. Lo anterior se afirma por la ampliación autónoma que se realice por Argentina. De igual manera afirmamos la inaplicabilidad de la normativa material mexicana por un tribunal de los restantes once Estados, cuando versen sobre las dos categorías mencionadas. Igualmente en este caso, pende la aplicación de la excepción de orden público.

37 www.oas.org/ juridico/spanish/firmas/b-54.html (fecha de consulta: 19 de mayo de 2006).

38 Idem.

39 Idem. 
En el caso argentino, la doctrina se lamenta de no haber aprovechado la oportunidad brindada por el artículo tercero convencional, y así haber ampliado dicho ámbito de aplicación material-personal. En este sentido, se afirma: "lamentamos que la Argentina no hubiere utilizado la facultad descripta extendiendo las virtudes que aporta la convención a las obligaciones alimenticias nacidas del parentesco. Así, mediante una declaración en tal sentido, se habría concretado una igualdad de tratamiento legal - a nivel internacional - tanto para las relaciones concernientes a las cónyuges entre sí; las surgidas a consecuencia de la patria potestad; y las originadas en el vínculo de parentesco". ${ }^{40}$

En parecidos términos y con iguales efectos a los señalados en la República de Argentina, consta la anotación que hizo Ecuador, quien señaló: "Designación de Autoridad Central (13 de enero de 2005) con fecha 13 de enero de 2005, el gobierno de Ecuador designó a la siguiente Autoridad Central con respecto a la Convención Interamericana sobre Obligaciones Alimentarias: doctor Iván Gomezjurado Cevallos, presidente. Consejo Nacional de la Niñez y la Adolescencia. Edificio Tarqui, Santa María y Amazonas, Quito, Ecuador".

Así, podemos afirmar que de este silencio convencional debemos recurrir a la normativa material autónoma de Ecuador para ver la eficacia extraterritorial que tendrá la sentencia mexicana que se pronuncia sobre la obtención de alimentos a favor de parientes colaterales hasta el cuarto grado, menores e incapaces y concubinos. Lo anterior se desencadena desde que Ecuador no amplía los acreedores alimentarios por esta vía. Igual que se afirmaba para Argentina, en el caso de Ecuador sostenemos que no habrá dificultad de eficacia extraterritorial cuando la sentencia se pronuncia sobre adoptantes y adoptados. Iguales afirmaciones lanzamos para el caso de ser determinada la normativa material mexicana sobre estas dos categorías, para reconocer a los acreedores alimentarios.

\section{Belice, Bolivia, Brasil, Costa Rica, Paraguay, Perú y Uruguay}

En el caso de Belice, que depositó su instrumento de ratificación de la convención el 16 de julio de 1997; Bolivia, que depositó su instrumento de ratificación el 8 de octubre de 1998; Brasil, quien depositó su instrumento de ratificación el 11 de julio de 1997; Costa Rica, que depositó

40 Buis, Emiliano et al., "La República Argentina...", cit., nota 11, p. 86. 
el 26 de abril de 2001; Paraguay, que depositó el 20 de mayo de 1997; Perú, que depositó su instrumento de adhesión el 21 de diciembre de 2005 y Uruguay, que depositó el 31 de agosto de 2001, se hizo sin reservas, anotaciones ni declaraciones interpretativas.

Por lo anterior habrá que determinar el alcance de los acreedores alimentarios de conformidad con lo dispuesto en la normativa autónoma de cada uno de los Estados que mencionamos. Volvemos a encontrar dos categorías en peligro, los concubinos y los parientes colaterales hasta el cuarto grado, donde pronosticamos la falta de eficacia extraterritorial del pronunciamiento mexicano por aplicación de la excepción de orden público. Igualmente nuestro pronóstico se encamina a afirmar la inaplicabilidad de la normativa material mexicana cuando a estas dos categorías se refiera.

\section{Guatemala}

En el caso de Guatemala, que depositó su instrumento de ratificación el 5 de febrero de 1996, se realiza una declaración interpretativa en los siguientes términos:

La Delegación de Guatemala desea hacer constar su interpretación acerca de lo dispuesto por el artículo 11 de la Convención Interamericana sobre Obligaciones Alimentarias. Conforme a la ley procesal civil vigente en Guatemala, norma que tiene carácter de ley de orden público y que es aplicable al caso de esta convención, para reconocer eficacia extraterritorial a una sentencia extranjera se requiere, inter alia, que ésta no se haya dictado en rebeldía del demandado y que en el país donde se dictó reconozca igual eficacia a las sentencias nacionales. En consecuencia, con el propósito de no insertar en el texto de la convención requisitos que no son aplicables a otros países y para no desvirtuar uno de los principales propósitos de este instrumento cual es la cooperación internacional, Guatemala interpreta los incisos e) y f) del artículo 11 en el sentido de su ley procesal vigente, es decir, que la sentencia no haya sido dictada en rebeldía del demandado. Además. Guatemala interpreta que el requisito de la efectividad extraterritorial recíproca se cumple en el caso que el Estado extranjero cuya sentencia se pretenda hacer efectiva en Guatemala, sea parte ratificante de la convención al igual que el Estado de Guatemala.

De esta declaración que realiza Guatemala a la hora de ratificar no se desprende un aumento o disminución de los acreedores de alimentos, lo 
cual desemboca necesariamente en la toma en consideración de la normativa autónoma guatemalteca. Lo anterior y en el sentido que venimos predicando en los dos sub-apartados anteriores, afirmamos que los pronunciamientos de México a favor de los concubinos y de los parientes colaterales hasta el cuarto grado, menores e incapaces, tendrán un obstáculo para obtener su eficacia por la aplicación del correctivo del orden público, así como la inaplicabilidad de la normativa material mexicana para resolver el fondo de la pretensión de alimentos, por la aplicación del mismo correctivo.

\section{Panamá}

Panamá realiza, al tiempo de ratificar, el 18 de marzo de 1999, una declaración interpretativa en los siguientes términos:

La República de Panamá de conformidad con el artículo 3 de la citada convención, y de acuerdo al ordenamiento jurídico interno, declara que los alimentos comprenden una prestación económica, que debe guardar la debida relación entre las posibilidades económicas de quien está obligado a darlos y las necesidades de quien o quienes los requieren. Estos comprenden: el suministro de sustancias nutritivas o comestibles, de atención médica y medicamentos; b) las necesidades de vestido y habitación; $c$ ) la obligación de proporcionar los recursos necesarios a fin de procurar la instrucción elemental o superior o el aprendizaje de un arte u oficio, aún después de la mayoría de edad hasta un máximo de veinticinco (25) años, si los estudios se realizan con provecho tanto en tiempo como en el rendimiento académico, salvo si se trata de un discapacitado profundo, en cuyo caso hasta que éste lo requiera; $d$ ) tratándose de menores, todo lo necesario para lograr su desarrollo integral desde la concepción. Están también obligados recíprocamente a dar alimentos: a) los cónyuges y, b) los ascendientes y descendientes. Los hermanos sólo se deben los auxilios necesarios para la vida, cuando los necesiten por cualquier causa que no sea imputable al alimentista y se extenderá en su caso a los que precisen para su educación. La reclamación de alimentos cuando proceda y sean dos (2) o más los obligados se hará por el siguiente orden: a) al cónyuge; $b$ ) a los descendientes de grado más próximo; c) a los ascendientes, también de grado más próximo; $d$ ) a los hermanos, pero están obligados en último lugar los que sólo sean de vínculo sencillo. Entre los descendientes y ascendientes, se regulará la gradación por el orden en que sean llamados a la sucesión intestada o legal de la persona que tenga derecho a los alimentos. $\mathrm{Si}$ la persona llamada en grado anterior a la prestación no estuviera en condi- 
ciones de soportar la carga en todo o en parte, dicha obligación será puesta en todo o en parte a cargo de las personas llamadas en grado posterior. En la sentencia que declara el divorcio, el juez puede conceder una pensión alimenticia al cónyuge inocente a cargo del culpable. Esta pensión se calculará de modo que el cónyuge conserve la posición social que tenía durante el matrimonio, y se revocará cuando deje de ser necesaria, o cuando el beneficiario contraiga nuevas nupcias. En este sentido, la persona concebida que está por nacer (el nasciturus) tiene derecho a pensión alimenticia prenatal.

Observamos que a pesar de realizar esta interesante declaración interpretativa nunca lo extiende a los acreedores que alcanza la República Mexicana. Así, se darán alimentos en línea recta sin límites y en la línea colateral hasta el segundo grado, es decir, hermanos. De esta forma volvemos a situar la problemática en los mismos términos y limitaciones que en los apartados anteriores. Así, encontraremos inaplicabilidad de la normativa material mexicana y falta de eficacia extraterritorial de las sentencias mexicanas cuando se base en las dos categorías problemáticas que venimos señalando.

\section{Conclusión}

De lo anterior se desprende que existen cuatro bloques de Estados en cuanto a su postura frente a la convención, a saber, primero, Argentina y Ecuador, cuya anotación se destina a clarificar su autoridad central; segundo, Belice, Bolivia, Brasil, Costa Rica, Paraguay, Perú y Uruguay quienes a la hora de ratificar no hicieron declaración interpretativa o reserva alguna; un tercer bloque conformado por Guatemala quien hace una declaración que nada tiene que ver con la problemática planteada en estas líneas y, finalmente, el cuarto grupo, Panamá, que a pesar de hacer una declaración interpretativa en el sentido de los acreedores alimentarios, no llega a los límites planteados por México. En este sentido nos interesa la declaración interpretativa de México y Panamá desde que hicieron una declaración interpretativa en el sentido que lo admite el artículo tercero de la Convención Interamericana sobre Obligaciones Alimentarias.

\section{AMPLIACIONES Y REGULACIÓN AUTÓNOMAS}

Si éste es el panorama descrito en el ámbito convencional, no esperamos mucho cambio en el panorama autónomo. Estimamos que las decla- 
raciones interpretativas que se realizan por un Estado a una determinada convención se realizan en aras de darle continuidad y armonización a este cuerpo normativo con los ya existentes. Por eso las sorpresas estimamos que no serán muy grandes. De cualquier forma entremos a su estudio y análisis.

De los once Estados parte de esta convención nos interesa saber cómo está regulada la obligación de alimentos en sus respectivos códigos civiles o códigos de familia. Lo anterior nos servirá de guía para saber quiénes son los acreedores alimentarios en cada uno de ellos, y por ende, las posibilidades de alegación del orden público en las tres categorías ampliadas por la República Mexicana; esto servirá para alcanzar la conclusión sobre la posibilidad de reconocer y ejecutar una sentencia mexicana que versa sobre alimentos entre concubinos y/o entre parientes colaterales hasta el cuarto grado, menores e incapaces. De igual modo, para saber las posibilidades de que la normativa material mexicana sea aplicada para resolver el fondo de la pretensión, cuando apunta a las tres categorías que mencionamos. Eficacia extraterritorial y aplicabilidad de normativa material extranjera que tendrá como peligro la aplicación de la excepción de orden público. Veamos dichos términos de conformidad con las categorías que denominados "sensibles".

\section{Prestación de alimentos entre adoptantes y adoptados}

En este apartado intentaremos ver qué Estados permiten la prestación de alimentos en la categoría de la adopción. Auguramos que no habrá sorpresas negativas en los distintos códigos de familia o códigos civiles; por ende se espera, como es lo lógico, que se otorguen alimentos en estas categorías sin limitaciones o exclusiones.

Por orden alfabético señalamos que Argentina permite tal prestación sin límite alguno; ${ }^{41}$ por su parte, el Código de Familia de Bolivia apunta en el mismo sentido que el argentino, por lo que no habrá problema alguno de prestación de alimentos en esta categoría; ${ }^{42}$ el Código Civil de Brasil afirma en términos algo más discretos lo mismo; ${ }^{43}$ en parecidos térmi-

\footnotetext{
41 En el caso argentino, tenemos los artículos 240, 323, 329 y 335 de su Código

42 En el Código de Familia de Bolivia encontramos los artículos 12, 16 y 215.

43 En el Código Civil de Brasil encontramos los artículos 1625 y 1626.
} Civil. 
nos está redactado el Código de Familia de Costa Rica;44 Ecuador; ${ }^{45}$ Panamá; ${ }^{46}$ Paraguay; ${ }^{47}$ Perú ${ }^{48}$ y Uruguay. ${ }^{49}$

De las anteriores líneas se desprende que la sentencia mexicana respecto de alimentos emitida a favor de las calidades de adoptante y adoptado, será reconocida y ejecutada sin posibilidades de alegación de la excepción de orden público. En este mismo sentido, aprovechamos para señalar que en el caso de que la normativa material mexicana sea la señalada por la norma conflictual para dar respuesta al fondo de la pretensión, será aplicada sin posibilidad de alegar la misma excepción o correctivo. De esta forma afirmamos que las sentencias mexicanas tendrán eficacia extraterritorial en los países que mencionamos.

\section{Prestación de alimentos a parientes colaterales hasta cuarto} grado, menores e incapaces

En este apartado, el orden en el que se examinarán la categoría de los parientes colaterales hasta el cuarto grado, menores e incapaces, volverá a ser el alfabético.

En el caso argentino, la información de la que disponemos apunta a la obtención de alimentos hasta los hermanos (o medio hermanos), es decir a los parientes colaterales hasta el segundo grado; ${ }^{50}$ el mismo límite se observa en el caso de Bolivia, donde su Código de Familia prevé a los hermanos, con preferencia los de doble vínculo sobre los unilaterales, y entre éstos los maternos sobre los paternos; así, se estanca en los parien-

44 Respecto al Código de Familia de Costa Rica, las prestaciones de alimentos entre adoptantes y adoptados la encontramos los artículos 100 y 102.

45 En el título XIII, del Código Civil de Ecuador, titulado "De la adopción", encontramos en concreto los artículos 332, 344 y el artículo 345.

46 En el caso de Panamá, encontramos el Código de la Familia de Panamá, artículos 21, 22, el artículo 236 y 237.

47 En el Código Civil de Paraguay encontramos el artículo 255, el 256.

48 Por lo que se refiere a la adopción el Código Civil de Perú lo regula en el artículo 238 у 377.

49 Respecto al Código de Familia uruguayo encontramos el artículo 250.

50 En Argentina, el Código Civil apunta alimentos para cónyuges (artículos 162, 198, 207, 208, 209, 210, 2221, 222, 228, 236 y 271); los parientes por consanguinidad, es decir, los ascendientes y descendientes, los hermanos y medio hermanos y los parientes por afinidad (artículos 367 y 368); la figura de la tutela (artículos 412 y 429); donaciones (artículo 1858) y legado (artículo 3790). 
tes colaterales hasta el segundo grado; ${ }^{51}$ hasta este grado se extiende también la obligación de Brasil;:52 Costa Rica; ${ }^{53}$ Ecuador; ${ }^{54}$ Guatemala; 55 Panamá: ${ }^{56}$ Paraguay; ${ }^{57}$ Perú ${ }^{58}$ y Uruguay. ${ }^{59}$

51 Por su parte, el Código de Familia de Bolivia, en su artículo 15, afirma que "1o. el cónyuge, 2o. los padres y, en su defecto, los ascendientes más próximos de éstos, 3o. los hijos y, en su defecto, los descendientes más próximos de éstos, 4o. los hermanos, con preferencia los de doble vínculo sobre los unilaterales, y entre éstos los maternos sobre los paternos, 5o. los yernos y las nueras, 6o. el suegro y la suegra", y en su artículo 17 señala la asistencia a los hermanos mayores y a los afines.

52 De conformidad con el Código Civil de Brasil (artículo 1590) se apunta a los hijos menores y a los mayores incapaces; padres-hijos y ascendientes (artículo 1696); descendientes y hermanos (artículo 1697); herederos del deudor (artículo 1700); separación judicial litigiosa (artículo 1702), hijos habidos fuera del matrimonio (artículo 1705) y tutor (artículo 1740).

53 El Código de Familia de Costa Rica, en su título IV, artículos 169 y 170, señala a los cónyuges, los padres a los hijos menores o incapaces y los hijos a sus padres, los hermanos a los hermanos menores o los que presenten una discapacidad física que les impida valerse por sí mismos, los abuelos a los nietos menores y a los que, por una discapacidad, no puedan valerse por sí mismos, los nietos y bisnietos a los abuelos y bisabuelo.

54 En el Código Civil para Ecuador, en su título XV (artículo 367) menciona al cónyuge, a los hijos, a los descendientes, a los padres, a los ascendientes, a los hermanos y al que hizo una donación cuantiosa. Se añade el artículo 371 que habla de los incapaces.

55 El artículo 211 del Código Civil de Guatemala de 1956, única versión encontrada, señala a los cónyuges, ascendientes y descendientes; el 212 señala a los hermanos y medio hermanos.

56 El Código de la familia de Panamá, en su título VII, capítulo I, artículo 378 señala a los cónyuges, los ascendientes y descendientes. Señalando de manera limitada a los hermanos.

57 La siguiente nota ha tenido en cuenta las modificaciones introducidas por la Ley núm. 1/92 de reforma parcial del Código Civil, que el Congreso de la Nación Paraguaya sanciona con fuerza de ley. En el caso de Paraguay, el Código Civil paraguayo, de 1985, con las reformas apuntadas en el tema que nos interesa, señala, capítulo XII, sección II (artículo 258) a los cónyuges, los padres y los hijos, los hermanos, los abuelos, y en su defecto, los ascendientes más próximos y los suegros, el yerno y la nuera. Los descendientes la deberán antes que los ascendientes; (artículo 76) divorcio, de la separación personal y disolución de la comunidad conyugal.

58 En el Código Civil de Perú (artículo 58) se afirman alimentos para herederos forzosos del ausente, del cónyuge del ausente; (artículo 345) patria potestad y separación convencional; (artículos 398 y 473) hijo mayor de edad; (artículo 474) cónyuges, los ascendientes y descendientes, los hermanos.

59 En el caso de Uruguay en su Código Civil (artículo 122) habla de los hijos menores a sus padres en todo caso y las demás personas con derecho a recibirlo por razón 
De las anteriores afirmaciones se deducen dos consecuencias inevitables. La primera que supone que el pronunciamiento judicial mexicano que otorga alimentos más allá de los parientes colaterales en segundo grado (hermanos/medio hermanos) tendrá el correctivo del orden público que actuará de manera implacable. De tal forma que no hay posibilidad de que una sentencia mexicana obtenga eficacia extraterritorial en los países mencionados, desde que se alege excepción de orden público cuando se refiera la prestación de alimentos para parientes colaterales hasta cuarto grado, menores e incapaces. La segunda consecuencia que anunciábamos se centra en la inaplicabilidad de la normativa material mexicana cuando ésta sea la elegida por la norma conflictual del tribunal que se declaró con competencia para conocer el supuesto de hecho, privado y con elemento de internacionalidad. Dicha inaplicabilidad se dará por el levantamiento de la excepción de orden público.

\section{Prestación de alimentos para concubinos}

Para finalizar con las tres categorías denominadas "sensibles", queda analizar la posibilidad de dar eficacia extraterritorial a una sentencia mexicana cuando otorgue alimentos entre concubinos.

En el caso de Argentina no se desprende del Código Civil argentino la posibilidad de otorgar alimentos en este supuesto de hecho. Lo anterior implica necesariamente la consiguiente alegación de orden público ante el intento de dar eficacia extraterritorial a una sentencia mexicana o al momento de que un juez argentino deba aplicar la normativa material mexicana para dar respuesta al fondo de la pretensión. En el caso de Bolivia, el Código de Familia no habla sobre la posibilidad de otorgar alimentos en este supuesto. Lo anterior deriva en las mismas consecuencias explicadas en el caso anterior. De este modo toparemos con la excepción de orden público cuando intentemos dar eficacia extraterritorial a una sentencia mexicana en este país que se base en este supuesto concreto. También, toparemos con la misma excepción cuando se trate de aplicar la normativa material mexicana en este concreto supuesto. En el caso de Brasil, su Código Civil regula en los artículos 1694 a 1710 la figura de los alimentos. Es un código que nos ha sorprendido gratamente desde que en 
su artículo 1694 afirma que "pueden los parientes, los cónyuges o compañeros pedirse unos a otros los alimentos que necesiten para vivir de modo compatible con su condición social, inclusive para atender las necesidades de su educación" (cursivas mías). Entendemos por "compañeros" a los concubinos. De esta forma se desprende que una sentencia mexicana que otorgue alimentos a los concubinos, en función de la declaración interpretativa convencional, tendrá plenos efectos en Brasil, al no poder ser considerado como contrario a su orden público. De igual forma la aplicación de la normativa material mexicana no puede ser rehusada en esta categoría por la aplicación del orden público. En el caso de Costa Rica, de su Código de Familia no nos consta la posibilidad de dar alimentos en esta categoría, lo anterior deriva en las consecuencias señaladas. En el caso de Ecuador tampoco nos consta la posibilidad de dar alimentos a los concubinos de conformidad con esta normativa. De lo anterior se desprende el posible levantamiento de la excepción de orden público en los dos momentos procesales que venimos señalando, es decir, en la fase de aplicación del derecho y en la fase de eficacia extraterritorial del pronunciamiento. En el caso de Guatemala no encontramos una regulación del concubinato y por ende de la obligación de prestarse alimentos entre concubinos. En Panamá tampoco encontramos regulación de alimentos para concubinos. En Paraguay respecto a la unión de hecho o concubinato, la Ley 1/92 realizó las siguientes modificaciones; artículo 83: "la unión de hecho constituida entre un varón y una mujer que voluntariamente hacen vida en común, en forma estable, pública y singular, teniendo ambos la edad mínima para contraer matrimonio y no estando afectados por impedimentos dirimentes producirá efectos jurídicos conforme a la presente ley"; artículo 84: "en la unión que reúna las características del artículo precedente y que tuviera por lo menos cuatro años consecutivos de duración se crea entre los concubinos una comunidad de gananciales, que podrá disolverse en vida de ambos o por causa de muerte; debiendo en los dos casos distribuirse los gananciales entre los concubinos, o entre el sobreviviente y los herederos del otro, por mitades"; por su parte, el artículo 85 señala que "cuando la unión expresada hubieren nacido hijos comunes el plazo de duración se considerará cumplido en la fecha del nacimiento del primer hijo"; artículo 86: "después de diez años de unión de hecho o concubinaria bajo las condiciones expresadas, podrán los concubinos mediante declaración conjunta formulada ante el encargado del Registro del Estado Civil o el juez de Paz, de la jurisdic- 
ción respectiva, inscribir su unión, la que quedará equiparada a un matrimonio legal, incluso a los efectos hereditarios y los hijos comunes se considerarán matrimoniales. Si uno solo de los concubinos solicita la inscripción de la unión, el juez citará al otro concubino y luego de escuchar las alegaciones de ambas partes decidirá en forma breve y sumaria; artículo 87: "los bienes comunes de los concubinos que son los adquiridos por cualquiera de ellos durante la vida en común, están afectados a la satisfacción de las necesidades de la familia e hijos menores. Su administración corresponde a cualquiera de ellos, indistintamente. Los bienes propios, que son los que cada uno tenía antes de la unión o adquiridos durante ella por título propio, están bajo la administración y disposición de su titular"; artículo 88: "los gastos que cada uno de los concubinos realice en beneficio de la familia así como las obligaciones contraídas a tal efecto, obligan a ambos y se abonarán con los bienes comunes. Si éstos fueran insuficientes se hará con los bienes de cada uno, proporcionalmente"; artículo 89: "Se presumen hijos del concubino los nacidos durante la unión de éste con la madre, salvo prueba en contrario"; artículo 90: "Si terminada la convivencia y efectuada la separación de gananciales uno de los ex-concubinos careciere de recursos y estuviere imposibilitado de procurárselos, podrá solicitar alimentos al otro mientras dure la emergencia"; artículo 91: "Si la unión termina por muerte de uno de los concubinos siempre que ella tuviera cuanto menos cuatro años de duración el sobreviviente recibirá la mitad de los gananciales y la otra mitad se distribuirá entre los hijos del fallecido, si los hubiere. Si el causante tuviere bienes propios, el concubino supérstite concurrirá con los hijos en igualdad de condiciones de éstos. El derecho de representación del concubino supérstite sólo se extiende a sus descendientes en primer grado"; artículo 92: "Si el fallecido no tuviere hijos pero dejare ascendientes, el concubino sobreviviente concurrirá con ellos en la mitad de los gananciales, por partes iguales"; artículo 93: "Si el causante no tuviere descendientes ni ascendientes, el concubino supérstite recibirá todos los bienes del mismo, excluyendo por tanto a los colaterales"; artículo 94: "El supérstite en las uniones de hecho que tuvieran cuanto menos cuatro años de duración, gozará de los mismos derechos a las jubilaciones, pensiones e indemnizaciones que correspondan al cónyuge. El libro IV del Código Civil "De los derechos reales o sobre las cosas"; título IV "Bien de familia"; artículo 95, señala que "Podrán beneficiarse con la institución del bien de familia: 2) El concubino varón o mujer, cualquiera sea la 
naturaleza de dicha relación; 3) Los hijos biológicos y adoptivos, menores de edad y los incapaces aunque fuesen mayores". Para el caso de Perú no nos consta que esta categoría esté cubierta por la normativa autónoma peruana en cuanto a la prestación de alimentos. En este sentido los efectos y las consecuencias se repiten. Finalmente Uruguay parece que tampoco cuenta con una ley de concubinato en este sentido. ${ }^{60}$

\section{CONCLUSIONES}

Como colofón a todo lo afirmado en las líneas precedentes, debemos afirmar que la declaración interpretativa que hizo México tiene un efecto y un impacto muy limitado. Mientras que las sentencias emitidas por el Poder Judicial mexicano en materia de alimentos que favorezcan a los menores, a los cónyuges y excónyuges tendrán plena eficacia extraterritorial en cualquiera de los Estados parte de esta convención, no podemos afirmar lo mismo de la categoría de los concubinos, con la sana excepción de Brasil y Paraguay, y de los parientes colaterales hasta cuarto grado, menores o incapaces, donde no hay una excepción que hacer.

Al igual que proclamamos la escasa eficacia extraterritorial de la sentencia mexicana, también proclamamos las pocas posibilidades de que un juez de uno de estos Estados aplique la normativa material mexicana para resolver el fondo de la pretensión cuando ésta se basa en una de estas dos categorías denominadas "sensibles".

Esta declaración interpretativa sólo tiene sentido cuando los tres sectores del derecho internacional privado estén vinculados con México; es decir, que el juez mexicano sea el juez con competencia internacional, que el derecho aplicable, la normativa material aplicable a la resolución del fondo sea la mexicana y pretenda darse eficacia a esa sentencia en México. De lo contrario, la excepción de orden público planearía en dos etapas procesales, en la etapa de aplicación del derecho y en la etapa de eficacia extraterritorial. Lo anterior conduce a reducir mucho las posibilidades, los supuestos de hecho en que se conecte con México todos y cada uno de los sectores del derecho internacional privado.

60 Hemos encontrado un proyecto de ley de concubinato en la que se otorgarían alimentos los concubinos. http://gaysprogresistasuruguayos.blogdiario.com/1145111760 (fecha de consulta: 19 de mayo de 2006). 
Las anteriores afirmaciones conducen a sostener que la declaración interpretativa realizada por la República Mexicana no es más que una extensión de sus compromisos ad extra, sin demasiada efectividad fuera de las fronteras jurisdiccionales mexicanas.

\section{BIBLIOGRAFÍA}

Álvarez DE LARA, Rosa María, "Introducción a la Convención Interamericana sobre Obligaciones Alimentarias", Revista de Derecho Privado, México, año 6, núm. 7, 1995.

BeCERra RAmírez, Manuel, "Genocidio", Cuestiones Constitucionales. Revista Mexicana de Derecho Constitucional, México, UNAM, Instituto de Investigaciones Jurídicas, núm. 14, 2006, p. 219.

BuIS, Emiliano et al., "La República Argentina y la Convención Interamericana sobre Obligaciones Alimentarias (CIDIP IV)", en CALVO CARAVACA, Alfonso Luis y CASTEllanos RuIZ, Esperanza (dirs.), El derecho de familia ante el siglo XXI: aspectos internacionales, Colex, 2003.

CORBElla DE SimONET, Beatriz et. al., "Breves reflexiones sobre la CIDIP IV en materia de obligaciones alimentarias", Revista Uruguaya de Derecho Procesal, núm. 2, 1989.

FERnÁNDEZ ARROYo, Diego Pedro, La codificación del derecho internacional privado en América Latina, Eurolex, 1993.

García Moreno, Víctor Carlos, "La conveniencia de que México ratifique la Convención Interamericana sobre Obligaciones Alimentarias”, Lex, Difusión y Análisis, 3a. época, año IV, núm. 33, 1998.

—_ "Las obligaciones alimentarias entre México y Texas y su relación con la Convención Interamericana", Responsa, año 3, núm. 13, 1998.

LANDONI SOSA, Ángel, "Las convenciones interamericanas sobre obligaciones alimentarias y restitución internacional de menores aprobadas en la CIDIP IV celebrada en Montevideo del 9 al 15 de julio de 1989", Revista Uruguaya de Derecho Procesal, núm. 2, 1989.

PÉREZ-DUARTE Y NOROÑA, Alicia Elena, "La interpretación jurisdiccional en materia de alimentos", Revista de Derecho Privado, México, año 9, núm. 25, 1998.

Pereznieto Castro, Leonel y Silva Silva, Jorge Alberto, Derecho internacional privado. Parte especial, México, Oxford, 2000. 
REMIRo Brotóns, Antonio, Derecho internacional público, Tecnos, 1987, p. 206.

REUTER, Paul, Derecho internacional público, Barcelona, Bosch, 1987.

SANTOS BELANDRO, Rubén, "Reclamaciones de alimentos en el ámbito iberoamericano", en CALVO CARAVACA, Alfonso Luis y CASTELLANOS RUIZ, Esperanza (dirs.), El derecho de familia ante el siglo XXI: aspectos internacionales, Colex, 2003.

VelÁZQUez ElizARrarás, Juan Carlos, Anuario Mexicano de Derecho Internacional, vol. VI, 2006. 